\title{
FACTORS DETERMINING OUTCOME AFTER SURGICAL RESECTION OF T3 AND T4 LUNG CANCERS OF THE SUPERIOR SULCUS
}

\author{
Valerie W. Rusch, MD \\ Kalpaj R. Parekh, MD ${ }^{a^{*}}$ \\ Larry Leon, MS $^{\mathrm{d}}$ \\ Ennapadam Venkatraman, $\mathrm{PhD}^{\mathrm{d}}$ \\ Manjit S. Bains, MD \\ Robert J. Downey, MD \\ Patrick Boland, $\mathrm{MD}^{\mathrm{b}}$ \\ Mark Bilsky, MD \\ Robert J. Ginsberg, MD
}

\begin{abstract}
Background: The treatment of superior sulcus lung cancers is evolving and preoperative chemotherapy is increasingly used. To establish a historical benchmark against which new therapies can be assessed, we reviewed our 24-year experience with patients undergoing thoracotomy for lung cancers of the superior sulcus.
\end{abstract}

Methods: Data were acquired through retrospective chart review. Overall
survival was calculated by the method of Kaplan and Meier, and prognostic
factors were examined by log rank and Cox proportional hazards modeling.

Results: From 1974 to 1998,225 patients underwent thoracotomy. The patients included 144 men $(64 \%)$ and 81 women with a median age of 55 years. The majority of patients $(55 \%)$ received preoperative radiation, but $35 \%$ did not have any preoperative treatment. Tumor stages were IIB (T3 N0) in $52 \%$, IIIA in $15 \%$, and IIIB in $27 \%$ of patients. Complete resection was achieved in $64 \%$ of T3 N0 tumors, $54 \%$ of T3 N2 tumors, and 39\% of T4 N0 tumors. Operative mortality was 4\%. Median survival was 33 months for stage IIB and 12 months for both stages IIIA and IIIB. Actuarial 5-year survivals were $46 \%$ for stage IIB, $0 \%$ for stage IIIA, and $13 \%$ for stage IIIB. By univariate and multivariable analyses, $\mathrm{T}$ and $\mathrm{N}$ status and complete resection had a significant impact on survival. Locoregional disease was the most common form of relapse.

Conclusions: Our results provide a benchmark against which new treatment regimens can be evaluated. Control of locoregional disease remains the major challenge in treating lung cancers of the superior sulcus. The potential benefit of preoperative chemotherapy or chemoradiotherapy must be assessed by whether it leads to higher rates of complete resection and a lower risk of local relapse. (J Thorac Cardiovasc Surg 2000;119:1147-53)
$\mathrm{N}$ on-small cell carcinoma of the lung (NSCLC) involving the superior sulcus was first described by Henry Pancoast ${ }^{1}$ in 1932. This uncommon form of NSCLC was considered incurable until 1956, when

From the Thoracic Surgery, ${ }^{a}$ Orthopedic Surgery, ${ }^{b}$ and Neurosurgery Services, ${ }^{\mathrm{c}}$ Department of Surgery, and the Biostatistics Service, ${ }^{\mathrm{d}}$ Department of Epidemiology and Biostatistics, Memorial SloanKettering Cancer Center, New York, NY.

Received for publication Aug 13, 1999; revisions requested Dec 1, 1999; revisions received Jan 11, 2000; accepted for publication Feb 1, 2000.

Address for reprints: Valerie W. Rusch, MD, Memorial SloanKettering Cancer Center, 1275 York Ave, Rm C-867, New York, NY 10021 (E-mail: ruschv@mskcc.org).

* Dr Parekh is a resident in General Surgery at the Lenox Hill Hospital, New York, NY, and was supported by a research fellowship from that institution.

Copyright (c) 2000 by The American Association for Thoracic Surgery

0022-5223/2000 $\$ 12.00+0 \quad \mathbf{1 2 / 1 / 1 0 6 0 8 9}$

doi:10.1067/mtc.2000.106089
Chardack and MacCallum ${ }^{2}$ reported the case of a patient who survived long term after surgical resection and postoperative radiation. Subsequently, Shaw, ${ }^{3}$ Paulson, ${ }^{4}$ and their associates found that preoperative radiation facilitated surgical resection and that this combined treatment was potentially curative. On the basis of their experience, preoperative radiation followed by surgical resection has been a standard of care for lung cancers of the superior sulcus for the past 25 years.

Although many small surgical series attest to the feasibility of this treatment regimen (Table I), survival at 5 years remains approximately $25 \%$ to $30 \%$. The recent success of combined modality therapy, especially induction chemotherapy, in the management of stage IIIA (N2) NSCLC has stimulated interest in applying this approach to lung cancers of the superior sulcus. As a result, the treatment of lung cancers of the superior sulcus is now in flux, with various combinations of 
Table I. Results of series reporting outcome after surgery for lung cancers of the superior sulcus

\begin{tabular}{|c|c|c|c|c|c|}
\hline $\begin{array}{l}\text { First author } \\
\text { (year) }\end{array}$ & $\begin{array}{l}\text { No. of } \\
\text { patients }\end{array}$ & $\begin{array}{c}\text { Preoperative } \\
\text { treatment }\end{array}$ & $\begin{array}{l}\text { Percent having } \\
\text { complete resection }\end{array}$ & $\begin{array}{l}\text { Two-year } \\
\text { survival }\end{array}$ & $\begin{array}{l}\text { Five-year } \\
\text { survival }\end{array}$ \\
\hline Paulson 4 (1975) & 61 & RT & NS & $34 \%$ & $26 \%$ \\
\hline Miller $^{10}(1978)$ & 26 & RT & NS & NS & $32 \%$ \\
\hline Attar $^{11}$ (1979) & 73 & RT & $48 \%$ & $23 \%(3 \mathrm{y})$ & NS \\
\hline Stanford $^{12}(1980)$ & 16 & RT & NS & NS & $49 \%$ \\
\hline Anderson $^{14}$ (1986) & 28 & RT & $50 \%$ & NS & $34 \%$ \\
\hline Devine $^{13}(1986)$ & 40 & $\mathrm{RT}$ & $70 \%$ & NS & $10 \%$ \\
\hline Shahian $^{16}(1987)$ & 18 & RT & $50 \%$ & $64 \%$ & $56 \%$ \\
\hline Wright $^{15}$ (1987) & 21 & RT & NS & $55 \%$ & $27 \%$ \\
\hline Sartori $^{20}(1992)$ & 42 & RT & NS & $38 \%$ & $25 \%$ \\
\hline Dartevelle $^{25}$ (1993) & 29 & None (postop RT) & NS & $50 \%$ & $31 \%$ \\
\hline Ginsberg $^{5}$ (1994) & 124 & RT & $56 \%$ & $45 \%$ & $26 \%$ \\
\hline $\operatorname{Maggi}^{22}(1994)$ & 60 & RT & $60 \%$ & NS & $17.4 \%$ \\
\hline Martínez-Monge ${ }^{24}$ (1994) & 18 & Chemo + RT & $76 \%$ & NS & $56 \%(4 \mathrm{y})$ \\
\hline Muscolino $^{21}$ (1997) & 15 & RT & $73 \%$ & NS & $26.6 \%$ \\
\hline
\end{tabular}

$R T$, Radiation; Chemo, chemotherapy; $N S$, not stated.

chemotherapy and radiation often being given in the preoperative period in a highly individualized manner. A prospective multi-institutional phase II trial (Intergroup trial 0160, SWOG trial 9416) is currently underway to test the use of concurrent induction chemotherapy and radiation followed by surgical resection in both T3 and T4 N0-1 lung cancers of the superior sulcus. It is important to have a large and reliable historical experience against which to assess the validity of this new regimen.

Our previous analysis, based on 124 patients, ${ }^{5}$ focused on the use of brachytherapy and found that this did not improve local control or survival. Instead, completeness and type of resection and nodal metastases seemed to be significant prognostic factors. These results prompted us to focus on careful preoperative staging and extended resections that might improve long-term outcome. The current series extends our previous experience and allows a more definitive analysis of factors affecting local control and survival, as well as sites of relapse, in patients undergoing surgery for both $\mathrm{T} 3$ and $\mathrm{T} 4$ lung cancers of the superior sulcus.

\section{Patients and methods}

Patients with NSCLC involving the apex of the lung and chest wall, associated with pain radiating down the arm with or without additional neurologic symptoms (eg, Horner syndrome), were identified from the institutional and thoracic service databases. The previously reported 124 cases were included, thereby providing for analysis a large experience spanning 24 years. Only patients treated by thoracotomy were analyzed.

A detailed retrospective chart review was performed and the following items were recorded: patient age and sex; histologic tumor type and TNM status; type of preoperative and postoperative treatment; type of operation; whether resection was complete; disease status at last follow-up contact; and, when appropriate, date and sites of relapse. A resection was considered complete if the surgeon recorded that all gross tumor was removed and the surgical margins were histologically free of disease (negative). When not available by chart review, follow-up information was obtained by direct communication with the patient, family, or referring physician.

Statistical analyses were performed with SAS and S Plus software (SAS Institute, Inc, Cary, NC). Survival probabilities were calculated by the product limit method of Kaplan and Meier. ${ }^{6}$ The prognostic significance of factors was tested in a univariate model by log rank statistic for categorical covariates and by proportional hazards regression for continuous covariates. Proportional hazards regression was used to test the prognostic significance of factors in a multivariable model. ${ }^{6-8}$

\section{Results}

From January 1974 through January 1998, 225 patients underwent thoracotomy for possible resection of an NSCLC of the superior sulcus. The demographic features and data about the type of preoperative treatment and operation performed are shown in Table II. The majority of patients were male, and there was a preponderance of nonsquamous tumors. Approximately two thirds of the patients received some form of preoperative therapy, most frequently radiation, in keeping with the traditional approach to the management of lung cancers of the superior sulcus. The median dose of preoperative radiation was $4248 \mathrm{cGy}$ (range 400-8000 cGy). The use of induction chemotherapy in $20 \%$ of patients reflects empiric extension of a now accepted treatment of stage IIIA (N2) NSCLC to the management of lung cancers of the superior sulcus. The lack of preoperative treatment in $35 \%$ of patients reflects individual surgeon choice to attempt a wide resection followed by high-dose external-beam radiation after the operation. 
Table II. Demographic features and treatment information about the 225 patients with NSCLC of the superior sulcus who underwent thoracotomy

\begin{tabular}{|c|c|c|}
\hline No of patients & 225 & \\
\hline Men & $144(64 \%)$ & \\
\hline Women & $81(36 \%)$ & \\
\hline \multicolumn{3}{|l|}{ Age (y) } \\
\hline Median & 55 & \\
\hline Range & $(32-84)$ & \\
\hline $25 \%$ & 49 & \\
\hline $75 \%$ & 63 & \\
\hline \multicolumn{3}{|l|}{ Histology (No. of tumors, $\%$ total) } \\
\hline Squamous & $70(35 \%)$ & \\
\hline Adenosquamous & $4(2 \%)$ & \\
\hline Adenocarcinoma & $98(50 \%)$ & \\
\hline Large cell & $25(13 \%)$ & \\
\hline \multicolumn{3}{|l|}{$\begin{array}{l}\text { Preoperative treatment } \\
\text { (No. of patients, \% total) }\end{array}$} \\
\hline Radiation only & $101(45 \%)$ & \\
\hline Chemotherapy only & $23(10 \%)$ & \\
\hline Chemotherapy + radiation & $22(10 \%)$ & \\
\hline None & $78(35 \%)$ & \\
\hline \multicolumn{3}{|l|}{$\begin{array}{l}\text { Type of operation } \\
\text { (No. of patients, \% total) }\end{array}$} \\
\hline Thoracotomy, no resection & $31(14 \%)$ & \multirow{4}{*}{$83(31 \%)$} \\
\hline Wedge/segmentectomy only & 29 & \\
\hline+ Chest wall resection & 39 & \\
\hline+ Chest wall + spine resection & $15 J$ & \\
\hline Lobectomy only & 91 & \multirow{4}{*}{$107(47 \%)$} \\
\hline+ Chest wall resection & 65 & \\
\hline+ Chest wall + spine resection & 28 & \\
\hline + Chest wall + subclavian vessels & 51 & \\
\hline Pneumonectomy only & $1\}$ & $4(2 \%)$ \\
\hline + Chest wall resection & 3 & $4(2 \%)$ \\
\hline
\end{tabular}

*Twenty-eight patients had NSCLC, not otherwise. specified.

The most frequent operation performed was a lobectomy, usually in conjunction with a chest wall resection (Table II). The use of a limited resection, either a wedge resection or segmentectomy, has been largely abandoned in light of our previous experience, ${ }^{5}$ which suggested that overall suravival was lower with limited resection than with lobectomy (Table III). The minority of patients who did not have a chest wall resection performed are those who had such a significant tumor regression with induction treatment that chest wall resection no longer seemed warranted at thoracotomy. The overall operative mortality for all patients who underwent thoracotomy was $4 \%$.

The final tumor TNM status and the number of patients in each tumor stage who had a complete resection and information about survival by stage are shown in Table IV. Among the 55 patients with T4 tumors, the most common site of T4 disease was the spine, which was affected in $34(62 \%)$ of those patients. The inclusion of patients in this series who had N2 disease
Table III. Types of pulmonary resection, rates of complete resection, and sites of first recurrence in the current series compared with our previous series

\begin{tabular}{lcc}
\hline & Previous series & Current series \\
$N=124$ & $N=101$ \\
& $(1974-1991)$ & $(1992-1998)$ \\
\hline Type of resection & & \\
$\quad$ Thoracotomy only & $24(19 \%)$ & $7(7 \%)$ \\
Wedge/segmentectomy & $69(56 \%)$ & $14(14 \%)$ \\
Lobectomy & $31(25 \%)$ & $76(75 \%)$ \\
Pneumonectomy & 0 & $4(4 \%)$ \\
No. of patients with complete resection & & \\
T3 & $54 / 101(53 \%)$ & $46 / 63(73 \%)$ \\
T4 & $15 / 23(65 \%)$ & $5 / 32(15 \%)$ \\
Sites of first recurrence & & \\
$\quad$ Locoregional & $45(36 \%)$ & $32(31.5 \%)$ \\
Distant & $21(17 \%)$ & $25(25 \%)$ \\
Locoregional + distant & 0 & $4(4 \%)$ \\
Unknown & $28(23 \%)$ & $7(7 \%)$ \\
\hline
\end{tabular}

reflects an era at our institution during the 1970s and early 1980s when mediastinoscopy was not routinely performed. Not surprisingly, our results indicate that a complete resection was more likely to be feasible in earlier stage tumors, being more frequent among T3 N0 tumors than among T3 N2 or T4 N0 tumors. The rate of complete resection for T3 N0 tumors was higher in our most recent experience $(73 \%)$ than it was for the first 124 cases reported $(53 \%)$. This may reflect changes in patient selection and surgical technique.

The median length of follow-up was 2 years (range 0-20 years). Information about overall survival and the relationship between this and several prognostic factors is shown in Figs 1 to 3. By univariate analyses, patients with stage IIB tumors (Fig 1) had a significantly better survival than those with stage IIIA or IIIB tumors $(P<$ $.01)$. There was no significant difference in survival between stages IIIA and IIIB $(P=.7)$. When the 3 largest groups of patients were compared, namely T3 $\mathrm{N} 0$ versus $\mathrm{T} 3 \mathrm{~N} 2$ and $\mathrm{T} 4 \mathrm{~N} 0$, the patients with T3 N0 tumors had a significantly better survival than the other 2 groups $(P<.001)$. There was no significant difference in survival between patients with T3 N2 tumors and those with T4 N0 tumors $(P=.8)$.

Additional univariate analyses indicated that complete resection (Fig 2) and N0 nodal status (Fig 3) also had a significant impact on overall survival. However, neither preoperative nor postoperative treatment had a significant impact on survival $(P=.06$ for preoperative and $P=.8$ for postoperative treatment).

Potential prognostic factors were then also examined in a multivariable analysis (Table V). These included patient age and sex, $\mathrm{T}$ and $\mathrm{N}$ status, the type of resec- 


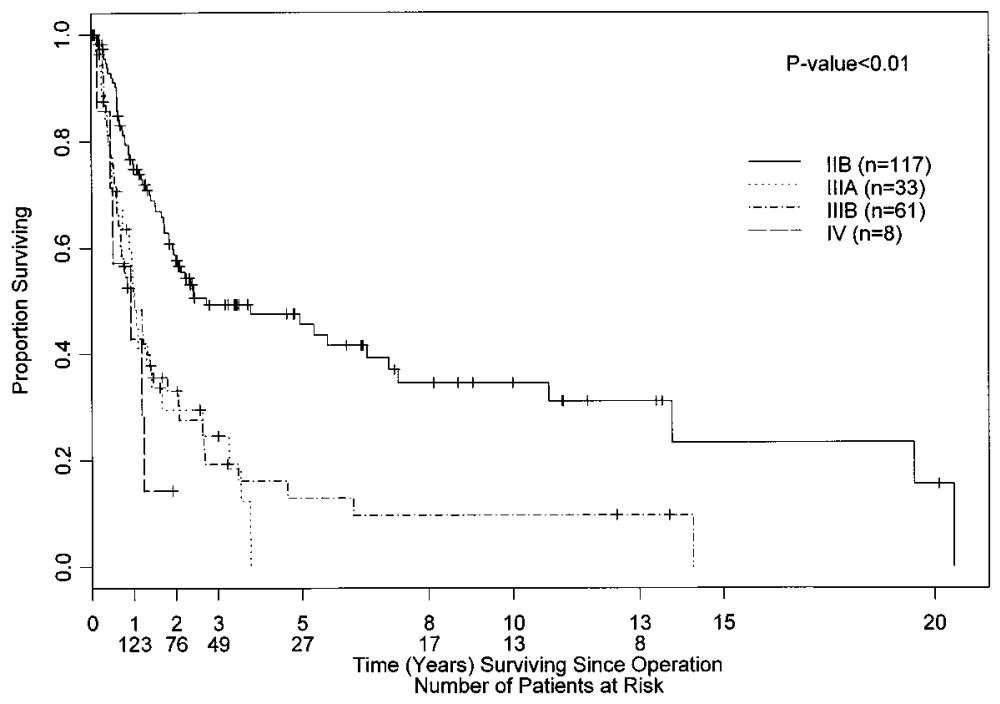

Fig 1. Survival curve estimates stratified by stage (IIB, IIIA, IIIB, IV).

Table IV. Information about stage, resectability, and survival among the 225 patients who underwent thoracotomy for lung cancers of the superior sulcus

\begin{tabular}{|c|c|c|c|c|c|c|}
\hline Stage & $T N M$ & $\begin{array}{c}\text { No. of } \\
\text { patients (\% total) }\end{array}$ & $\begin{array}{l}\text { No. of complete } \\
\text { resections (\%) }\end{array}$ & $\begin{array}{l}\text { Median survival } \\
(\text { mo) }(95 \% \text { CI })\end{array}$ & $\begin{array}{c}\text { Two-year survival } \\
(95 \% \text { CI) }\end{array}$ & $\begin{array}{c}\text { Five-year } \\
\text { survival }(95 \% \text { CI) }\end{array}$ \\
\hline 0 & T0 No M0 & 6 & 6 & $*$ & $*$ & * \\
\hline IIB & T3 No M0 & $117(52)$ & 75 (64) & $33(24,84)$ & $59 \%(50,69)$ & $46 \%(36,57)$ \\
\hline IIIA (n = 33) & $\begin{array}{l}\text { T3 N1 M0 } \\
\text { T3 N2 M0 }\end{array}$ & $\begin{array}{c}9 \\
24(10)\end{array}$ & $\begin{array}{c}7 \\
13(54)\end{array}$ & $12(8,20)$ & $29 \%(16,53)$ & $0 \%$ (N/A) \\
\hline \multirow[t]{5}{*}{ IIIB $(n=61)$} & T3 N3 M0 & 7 & 1 & $12(8,17)$ & $33 \%(22,49)$ & $13 \%(6,30)$ \\
\hline & T4 NX M0 & 2 & 0 & & & \\
\hline & T4 N0 M0 & $45(20)$ & $17(38)$ & & & \\
\hline & T4 N1 M0 & 6 & 2 & & & \\
\hline & T4 N2 M0 & 1 & 0 & & & \\
\hline \multirow[t]{4}{*}{$\mathrm{IV} \dagger(\mathrm{n}=8)$} & T3 N0 M1 & 4 & 2 & $*$ & $*$ & $*$ \\
\hline & T3 N1 M1 & 1 & 1 & & & \\
\hline & T3 N2 M1 & 2 & 1 & & & \\
\hline & T4 N2 M1 & 1 & 1 & & & \\
\hline
\end{tabular}

The $95 \%$ confidence intervals $(C I)$ are noted in parentheses under the median, 2-year, and 5-year survival figures.

"Number too small to calculate survival.

${ }^{\dagger} \mathrm{M} 1$, Solitary site, resected.

tion performed, the type of preoperative therapy, the histologic tumor type, and the completeness of resection. Only the completeness of resection and the $\mathrm{T}$ and $\mathrm{N}$ status still had a significant impact on overall survival.

Locoregional recurrence was the most common site of first relapse, occurring in $40 \%$ of patients (Table III). Information about the precise sites of locoregional relapse was available in 154 patients and is shown in Table VI. The most frequent sites were the spine, chest wall, and lung. Among patients with T4 tumors, half of all recurrences involved the spine.

\section{Discussion}

The management of NSCLC of the superior sulcus has evolved significantly during the past 4 decades. The early reports by Shaw, ${ }^{3,9}$ Paulson, ${ }^{4}$ Miller, ${ }^{10}$ Attar, ${ }^{11}$ and their associates focused on the feasibility of preoperative radiation and surgical resection and on the fact that lung cancers of the superior sulcus were not universally fatal, as assumed previously.

During the 1980s, several reports ${ }^{12-19}$ established the "Paulson regimen" of preoperative radiation followed by surgical resection as a standard of care that led to an approximate $30 \%$ survival at 5 years (Table I). From 


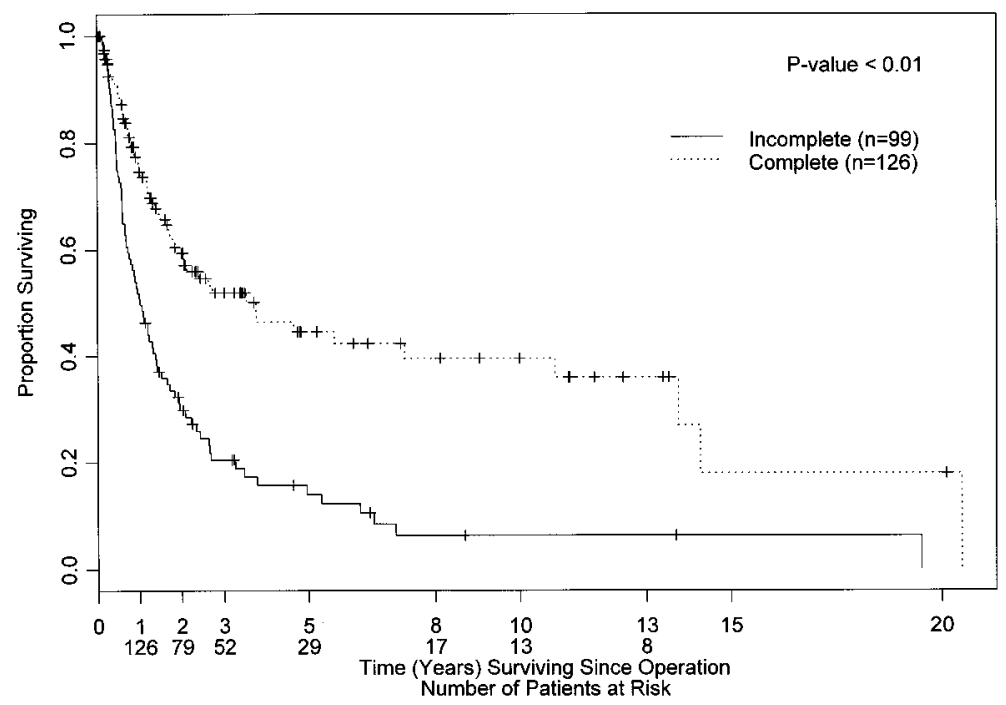

Fig 2. Survival curve estimates stratified by complete resection.

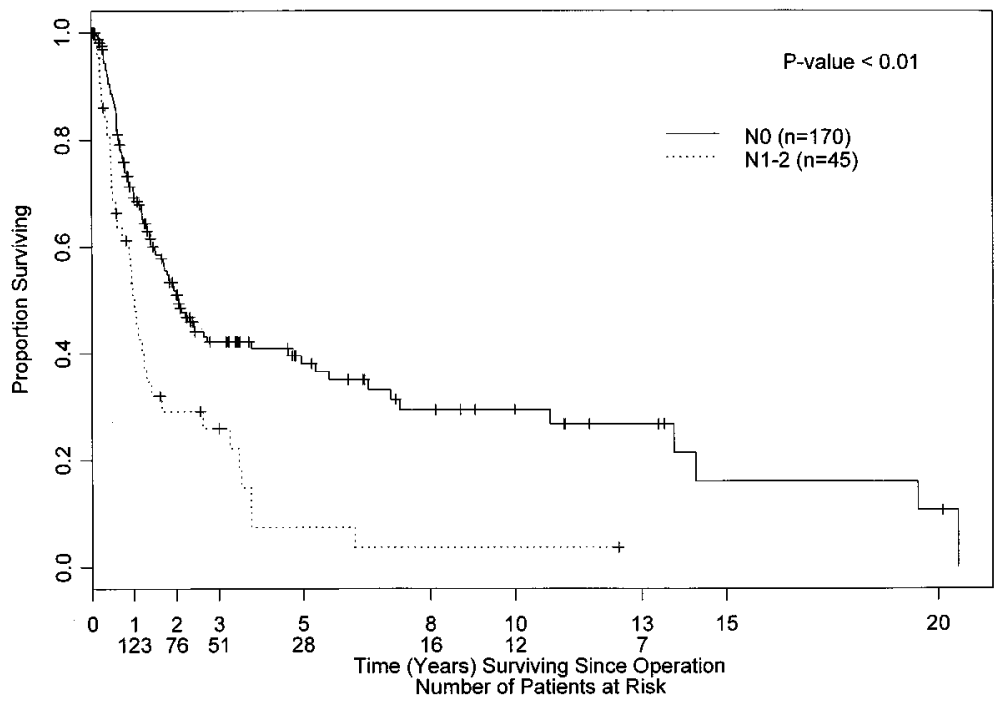

Fig 3. Survival curve estimates stratified by nodal status (N0, N1-2).

this experience it appeared that $\mathrm{N} 2$ disease, diseased (positive) margins, and vertebral body involvement might have an adverse impact on overall survival. ${ }^{4,14,20,21}$ However, the significance of these prognostic factors was not firmly established because published reports usually described small numbers of patients treated in variable ways over many years. Not all authors agreed on the poor prognostic impact of T4 disease so long as complete resection was achieved. ${ }^{15}$ On the other hand, there has been a growing recognition of the importance of mediastinoscopy and the fact that N2 disease, as for all other subsets of stage III NSCLC, was associated with the early development of distant metastases and an extremely poor survival. ${ }^{4,14,15}$

During the 1990s, reports have focused on defining prognostic factors, ${ }^{5,20-22}$ on determining the role of brachytherapy, ${ }^{5}$ and on exploring new techniques that facilitate complete resection of T4 tumors. ${ }^{18,23}$ Our previous analysis, based on 124 patients operated on from 1974 to 1991, showed that brachytherapy did not contribute significantly to local control and suggested that N2 disease, completeness of resection, T4 tumors, and, 
Table V. Results of the multivariable analysis of prognostic factors influencing overall survival

\begin{tabular}{lccc}
\hline & & \multicolumn{2}{c}{ Hazard ratio } \\
\cline { 3 - 4 } Prognostic factor $^{*}$ & P value & Estimated & $95 \%$ CI \\
\hline Wedge & .08 & 1.4 & $(1.0,2.1)$ \\
T4 & .05 & 1.6 & $(1.0,2.5)$ \\
IR & $<.01$ & 2.2 & $(1.4,3.3)$ \\
N1 or N2 & $<.01$ & 2.1 & $(1.4,3.2)$ \\
\hline
\end{tabular}

*Wedge/segment versus lobectomy; T4 versus T3; incomplete resection (IR) versus complete resection; $\mathrm{N} 1$ or $\mathrm{N} 2$ nodes versus N0 nodes.

to a lesser degree, limited pulmonary resection had an adverse impact on survival. Since then, mediastinoscopy, with or without scalene node biopsy, has been a routine part of our preresection evaluation of superior sulcus tumors. The neurosurgeons and orthopedic surgeons frequently participate in preoperative evaluation and surgical resection. Formal vertebral resection is performed whenever indicated to try to ensure complete resection of tumor abutting or involving the spine. Although common patterns of tumor invasion of the spine sometimes preclude en bloc resection, negative surgical margins can usually be obtained, at least for T3 tumors. However, our recent experience indicates that a complete resection is still not achieved for many T4 tumors.

Most recently, interest in exploring the potential benefit of preoperative chemotherapy has been increasing. The small series of 18 cases reported by MartínezMonge and associates ${ }^{24}$ suggests that induction chemoradiotherapy may improve the likelihood of pathologic complete response, local control, and overall survival. This approach to treatment is now being formally tested in a prospective multi-institutional clinical trial. Our current series, which includes almost twice the number of cases we reported previously, provides an important benchmark against which to assess the value of a new approach to treatment, because most of our patients had a surgical resection with preoperative and/or postoperative radiation with no consistent use of chemotherapy. Our current experience highlights several important aspects of the management of superior sulcus tumors. In addition to emphasizing the impact of $\mathrm{T}$ and $\mathrm{N}$ status on overall survival, it clearly demonstrates the importance of complete resection and the fact that only approximately half of all tumors are amenable to complete resection when managed in the traditional manner. Although the rates of complete resectability and 5-year survival are better for T3 N0 tumors (64\% and $46 \%$, respectively) than for the other TN subsets, they are still unacceptably low. This prob-
Table VI. Sites of locoregional relapse by $T$ status (some patients had more than one site of relapse)

\begin{tabular}{lcc}
\hline & $T 3(n=116)$ & $T 4(n=38)$ \\
\hline Lung & $31(27 \%)$ & $12(32 \%)$ \\
Chest wall & $33(28 \%)$ & $13(34 \%)$ \\
Pleura & $1(0.8 \%)$ & 0 \\
Spine & $21(18 \%)$ & $20(53 \%)$ \\
Brachial plexus & $5(4.3 \%)$ & $7(18 \%)$ \\
Mediastinum & 0 & $1(2.6 \%)$ \\
Subclavian vessels & 0 & 0 \\
\hline
\end{tabular}

lem is not usually emphasized, but a review of published series (Table I) indicates that our rate of incomplete resection is similar to that reported by other authors. Locoregional recurrence remains the predominant form of relapse for both $\mathrm{T} 3$ and $\mathrm{T} 4$ tumors, although this is obviously a greater problem for $\mathrm{T} 4$ tumors involving the spine. Future efforts to improve the results will entail not only a multidisciplinary approach to en bloc extended resection of adjacent structures, most frequently the spine, but also preoperative therapy that yields greater tumor regression, thereby improving the rates of complete resection that are so critical to long-term survival in this form of NSCLC.

Some of the patients in this series were operated on by Drs Nael Martini and Patricia McCormack (both retired) and by the late Dr Michael Burt. We thank Melody Owens for her expert assistance in manuscript preparation.

\section{REFERENCES}

1. Pancoast HK. Superior sulcus tumor. JAMA 1932;99:1391-6.

2. Chardack WM, MacCallum JD. Pancoast tumor: five-year survival without recurrence or metastases following radical resection and postoperative irradiation. J Thorac Surg 1956;31:535-42.

3. Shaw RR, Paulson DL, Kee JL Jr. Treatment of the superior sulcus tumor by irradiation followed by resection. Ann Surg 1961;7:29-40.

4. Paulson DL. Carcinomas in the superior pulmonary sulcus. J Thorac Cardiovasc Surg 1975;70:1095-104.

5. Ginsberg RJ, Martini N, Zaman M, et al. Influence of surgical resection and brachytherapy in the management of superior sulcus tumor. Ann Thorac Surg 1994;57:1440-5.

6. Kaplan EL, Meier P. Nonparametric estimation from incomplete observations. J Am Stat Assoc 1958;53:457-81.

7. Mantel N, Haenszel W. Statistical aspects of the analysis of data from retrospective studies of disease. J Natl Cancer Inst 1958;22:718-48.

8. Cox DR. Regression models and life tables [with discussion]. J R Stat Soc B 1972;34:187-220.

9. Shaw RR. Pancoast's tumor. Ann Thorac Surg 1984;37:343-5.

10. Miller JI, Mansour KA, Hatcher CR Jr. Carcinoma of the superior pulmonary sulcus. Ann Thorac Surg 1979;28:44-7. 
11. Attar S, Miller JE, Satterfield J, et al. Pancoast's tumor: Irradiation or surgery? Ann Thorac Surg 1979;28:578-6.

12. Stanford W, Barnes RP, Tucker AR. Influence of staging in superior sulcus (Pancoast) tumors of the lung. Ann Thorac Surg 1980;29:406-9.

13. Devine JW, Mendenhall WM, Million RR, Carmichael MJ. Carcinoma of the superior pulmonary sulcus treated with surgery and/or radiation therapy. Cancer 1986;57:941-3.

14. Anderson TM, Moy PM, Holmes EC. Factors affecting survival in superior sulcus tumors. J Clin Oncol 1986;4:1598-603.

15. Wright CD, Moncure AC, Shepard JO, Wilkins EW Jr, Mathisen DJ, Grillo HC. Superior sulcus lung tumors: results of combined treatment (irradiation and radical resection). J Thorac Cardiovasc Surg 1987;94:69-74.

16. Shahian DM, Neptune WB, Ellis FH Jr. Pancoast tumors: improved survival with preoperative and postoperative radiotherapy. Ann Thorac Surg 1987;43:32-8.

17. Hilaris BS, Martini N, Wong GY, Nori D. Treatment of superior sulcus tumor (Pancoast tumor). Surg Clin North Am 1987;67:965-76.

18. Hilaris BS, Martini N, Luomanen RKJ, Batata M, Beattie EJ Jr. The value of preoperative radiation therapy in apical cancer of the lung. Surg Clin North Am 1974;54:831-40.
19. Fuller DB, Chambers JS. Superior sulcus tumors: combined modality. Ann Thorac Surg 1994;57:1133-9.

20. Sartori F, Rea F, Calabrò F, Mazzucco C, Bortolotti L, Tomio L. Carcinoma of the superior pulmonary sulcus: results of irradiation and radical resection. $\mathrm{J}$ Thorac Cardiovasc Surg 1992;104:679-83.

21. Muscolino G, Valente M, Andreani S. Pancoast tumours: clinical assessment and long term results of combined radiosurgical treatment. Thorax 1997;52:284-6.

22. Maggi G, Casadio C, Pischedda F, et al. Combined radiosurgical treatment of Pancoast tumor. Ann Thorac Surg 1994;57:198-202

23. Sundaresan N, Hilaris BS, Martini N. The combined neurosurgical-thoracic management of superior sulcus tumors. J Clin Oncol 1987;5:1739-45.

24. Martínez-Monge R, Herreros J, Aristu JJ, Aramendía JM, Azinovic I. Combined treatment in superior sulcus tumors. Am J Clin Oncol 1994;17:317-22

25. Dartevelle PG, Chapelier AR, Macchiarini P, et al. Anterior transcervical-thoracic approach for radical resection of lung tumors invading the thoracic inlet. J Thorac Cardiovasc Surg 1993;105:1025-34. 